MEI

II, vol. 6

no 11

\title{
L'estat de la qüestió del patrimoni bibliogràfic en les biblioteques públiques de Catalunya
}

\author{
Victoria Rodrigo
}

\begin{abstract}
Resum
La presència del patrimoni bibliogràfic en les biblioteques públiques catalanes és un fet real, identitari i que singularitza la biblioteca que el posseeix. D’altra banda, l'observació de la realitat que ens porta a creure que la difusió del patrimoni no és una pràctica habitual en aquestes biblioteques i a plantjar-nos una hipòtesi: el patrimoni bibliogràfic de les biblioteques públiques - espai privilegiat de memòria- és un bé desconegut per la seva comunitat. Aquesta hipòtesi és el punt de partida del nostre treball. Una investigació en la que ens proposem assolir un objectiu principal: presentar l'estat de la qüestió del patrimoni bibliogràfic a les biblioteques públiques. I ho farem amb el testimoni d'onze biblioteques: BP de Girona, BP Gual i Pujadas, B J ordi Rubió i Balaguer, B Comarcal J osep Finestres, B Lambert Mata, BP de Lleida, B Margarida de Montferrat, B Marià Vayreda, BP de Tarragona, B Central de Terrassa, B Central Xavier Amorós.
\end{abstract}

Paraules clau

Biblioteca pública , difusió, patrimoni bibliogràfic, estat de la qüestió, entrevista.

Title

State of the art of the bibliographic heritage in the public libraries of Catalonia

\begin{abstract}
EducationThe presence of bibliographic heritage in Catalan public libraries becomes a real, and identity fact that distinguishes the library that owns it. Otherwise, the observation of reality leads us to believe that the heritage dissemination is not a common practice in these libraries and to ask ourselves a hypothesis: the bibliographic heritage of public libraries - memory-privileged space - is an unknown good for its community. This hypothesis is the starting point of this work. A research which aims at achieving the following primary goal: to present the state of art about the bibliographic heritage in public libraries. It will be performed with the testimony of eleven public libraries: Girona, Gual i Pujadas, Jordi Rubió i Balaguer, Comarcal Josep Finestres, Lambert Mata, Lleida, Margarida de Montferrat, Marià Vayreda, Tarragona, Central de Terrassa, and Central Xavier Amorós.
\end{abstract}

Keywords

Public library; Bibliographic heritage dissemination; State of the Art, Interview.

Rodrigo, Victoria . “L'estat de la qüestió del patrimoni bibliogràfic en les biblioteques públiques de Catalunya”. En: Métodos de información (MEI), II Época, Vol. 6, no 112015, pp. 215-236.

DOI: http:// dx.doi.o rg/ 10.5557/ IIMEI6-N11-215236 


\section{Introducció}

En aquest article mostrem les reveladores dades obtingudes durant la nostra investigació sobre les biblioteques públiques amb patrimoni bibliogràfic de Catalunya. Unes dades inèdites i no publicades fins ara, tot i que han servit de referència per complementar un treball final del Màster Biblioteques i Col-leccions Patrimonials de la Facultat de Biblioteconomia de la Universitat de Barcelona, presentat durant el mes de juliol de 2014 i del qual, recentment, s'ha estat editat part del seu contingut sota el títol: La difusió del patrimonio bibliogràfic a les biblioteques públiques: Un bé per descubrir (Arola Editors, 2015).

La investigació va començar amb l'observació d'una realitat que ens va portar a creure que la difusió del patrimoni no és una pràctica habitual en moltes biblioteques que fins ara s'han dedicat a dur a terme altres funcions i/o missions: formació permanent, foment de la lectura,...

Una suposició resultant de la nostra percepció, experiència professional i d'informacions recollides en trobades amb bibliotecaris i bibliotecàries.

La reflexió sobre aquesta realitat ens va fer plantejar una hipòtesi: el patrimoni bibliogràfic de les biblioteques públiques -espai privilegiat de memòria- és un bé desconegut per la seva comunitat. Aquesta hipòtesi serà el punt de partida del nostre estudi. Una investigació en la que ens proposavem assolir un objectiu principal: presentar l'estat de la qüestió del patrimoni bibliogràfic a les biblioteques públiques.

Per assolir aquest objectiu hem treballat diferents objectius específics:

1. Identificar la procedència de la col·lecció

2. Conèixer la tipologia del fons

3. Caracteritzar l'espai destinat a la seva consulta i conservació

4. Descriure el perfil dels grups d'usuaris i els requeriment d'informació que plantegen en relació al patrimoni bibliogràfic

5. Elaborar un catàleg d'accions de difusió

6.

La metodologia que hem seguit, pel tractament de les dades obtingudes i per demostrar la validesa de resultats en aquesta investigació, és la pròpia de la recerca no experimental amb disseny qualitatiu.

La tècnica emprada per recollir les dades ha estat l'entrevista, un model d'obtenció d’informació avalat per especialistes especialistes de prestigi 
(Merlinsky, 2006; Martín Muela-Meza, 2006).

Per tal que els resultats tinguessin valor científic era necessari garantir-ne la validesa i la confiança. Tots dos aspectes quedaran fermament demostrats en el transcurs d'aquest estudi.

Les biblioteques que hem estudiat formen part del Sistema de Lectura Pública de Catalunya (SLPC) i del Catàleg Col-lectiu del Patrimoni Bibliogràfic de Catalunya (CCPBC).

En aquest article exposem les metodologies emprades per la investigació i els resultats obtinguts. Uns resultats que mostraran l'estat de la qüestió del patrimoni bibliogràfic a les biblioteques públiques de Catalunya.

El nostre objectiu essencial és la descripció de les qualitats d'un fenomen: l'estat de la qüestió del patrimoni bibliogràfic a les biblioteques públiques de Catalunya, per això calia obtenir dades quantitatives, aspectes objectius, però també les perspectives i els punts de vista dels agents responsables i participants d'aquesta realitat, aspectes subjectius de l'experiència i del comportament humà.

El paradigma qualitatiu, també conegut per constructivista o naturalista, està influenciat per la filosofia fenomenològica de Husserl o Sartre, que considera el comportament humà massa complex per a reduir-lo a lleis universals.

Sabem que la cientificitat dels mètodes qualitatius que s'apliquen en les ciències socials encara és un tema de debat. A l'absència de mesures que facilitin la precisió cal afegir-hi els biaixos que introdueixen la subjectivitat d'observador i observat i que fan que els estudis qualitatius no gaudeixen del prestigi dels quantitatius en l'entorn científic.

Però en el nostre cas aquest tipus de recerca era l'únic aplicable i no esmerçarem recursos per fonamentar la seva confiança i validesa.

Aquest treball parteix d'una hipòtesi i per corroborar-la s'ha creat un model que inclou un conjunt d'indicadors simples que ofereixen un resum de la informació que necessitem. A la vegada, aquests indicadors simples presenten diferents atributs, que són els que hem de valorar a través dels ítems del qüestionari que hem elaborat.

En el camp de les entrevistes hi ha diferents variants: entrevista estructurada, semiestructurada o no estructurada; entrevista en profunditat; entrevista en grup (focus-grup) i l'entrevista amb grups (taller de recerca). 
Desprès de fer una exhaustiva revisió bibliogràfica, vam determinar que la més adient a la nostra finalitat era l'entrevista personal semiestructurada (Cea 2004; Díaz de Rada, 2005). Una entrevista guiada per un qüestionari, la qual presenta avantatges evidents com ara:

-Garantir la cobertura de tot el tema i el mateix ordre de preguntes amb cada entrevistat

-Establir els canals per a la direcció i delimitació del discurs

-Fixar tota l'atenció en el testimoni de l'entrevistat

La decisió d'optar per la modalitat d'entrevista personal en comptes de qüestionari per correu, va sorgir després de valorar diversos aspectes, com ara: la taxa de resposta més elevada en l'enquesta que en el qüestionari, el menor el risc d'errors d'interpretació, l'índex de respostes més completes, la possibilitat d'exercir més control sobre la mecànica pregunta-resposta, l'ordre, etc.

També, vam avaluar les limitacions que aquest sistema podia comportar com, per exemple: l'heterogeneïtat de respostes si no es controla bé, la lentitud i l'encariment d'aquesta formula vers l'enquesta i la dificultat d'anàlisi de la informació obtinguda.

Altrament, l'èxit d'una entrevista no se'l pot atribuir només a aquests factors. Alguns autors relacionen l'èxit de les entrevistes amb les habilitats de l'entrevistador, el seu coneixement del tema i el seu saber escoltar a l'entrevistat (Merlinsky 2006).

Amb totes aquestes premisses hem definit la nostra estratègia, la qual comença adquirint un coneixement tan exhaustiu com ens ha estat possible del tema a tractar per preparar acuradament tot el procés -elaboració del un guió, definició dels objectius, traducció de les qüestions a explorar en preguntes (Kvale, 1996).

El tipus de qüestionari que hem utilitzat és oral, presencial, obert i amb preguntes que no circumscriuen les respostes a unes opcions predeterminades. El primer contacte amb les entrevistades va ser telefònic per tal d'explicar-los la investigació que ens proposàvem realitzar i concertar una data per l'entrevista. Posteriorment, per un correu electrònic els vam avançar els temes a tractar, però no pas les preguntes concretes del qüestionari amb la finalitat d'evitar condicionar el grau de sinceritat de les respostes i que l'entrevista fos el més espontània possible. 
Les entrevistes s'han fet en les mateixes biblioteques en un clima de conversa fluida i natural. Començàvem amb una xerrada informal que servia per introduir breument el tema. Tot seguit, plantejàvem la bateria de preguntes, que ens ha permès aprofundir en el coneixement de les opinions i les actituds de les enquestades.

Buscàvem crear complicitats professionals. En aquest sentit, cal dir que les entrevistades han estat generoses en temps i en coneixements, per això el nostre agraïment és infinit.

La recollida de dades s'ha realitzat durant l'entrevista i, a posteriori, les hem tractat. L'organització de les dades en la recerca qualitativa es una tasca complexa i laboriosa que comença per traduir les respostes lliures a diferents categories que les resumeixin, les categoritzin, i les sistematitzin per després, analitzar les respostes.

Per tal que els resultats tinguin valor científic és necessari garantir-ne la validesa i la confiança. Tots dos aspectes quedaran fermament demostrats en el transcurs d'aquest estudi.

D’una banda, la confiança es basa en la garantia que el procés seguit es raonablement estable i consistent, tant en el temps que s'ha realitzar com a través de la investigació seguida des de la claredat en la hipòtesi, el paper de l'investigador dins de la situació de recerca, l'univers, la codificació i la validació de les dades per les persones entrevistades a posteriori.i

De l'altra, la validesa interna ha d'estar vinculada amb el fet de poder garantir que els fenòmens descrits i les causes presentades estan realment relacionades i que no hi intervenen significativament aspectes no explorats en la recerca. Es fonamenta en la presentació de descripcions significatives i riques en context, en la bona relació entre les dades presentades i les categories d'anàlisi, en la coherència interna dels fets presentats i en la revisió de les conclusions per part dels participants.

La validesa externa és la que fa referència a la possibilitat de reproduir per altri la recerca i així poder obtenir resultats equivalents. Per tot plegat és necessari mostrar la congruència entre allò trobat i la teoria en la qual es fonamenta la investigació, i descriure la mostra i els mètodes emprats detalladament per que puguin ser reproduïts i aplicats en altres escenaris.

La condició de patrimoni bibliogràfic està definida per llei, considera entre altres: «manuscrits rars i incunables, llibres, documents i publicacions antigues de interès especial (històric, artístic, científic, literari, etc.) solts o en 
col·leccions». ii Les col-leccions bibliogràfiques en les biblioteques estan formades per aquest exemplars però també per altres que són seleccionats per bibliotecaris amb un criteri més ampli.

El marc legal d'àmbit estatal i autonòmic regula la gestió del patrimoni bibliogràfic a les biblioteques amb normativa específica de competència estataliii i catalana. ${ }^{\text {iv }}$ També defensa l'accés al patrimoni «el acceso a la cultura, a la que todos tienen derecho»» , des de la Constitució.

A partir d'aquest marc legal, que defineix i promou l'accés a aquest béns patrimonials, s'ha volgut estudiar la difusió que del patrimoni bibliogràfic a les biblioteques públiques de Catalunya. Amb aquesta finalitat hem escollit les biblioteques que alhora formen part del Sistema de Lectura pública de Catalunya i del Catàleg Col·lectiu del Patrimoni Bibliogràfic de Catalunya. El Sistema de Lectura pública de Catalunya (SLPC) és el conjunt organitzat de serveis de biblioteca pública de Catalunyavi. Està regulat pels reglaments dictats pel Govern de la Generalitat i les biblioteques que formen part dibuixen el Mapa de lectura pública.vii

El Catàleg Col·lectiu del Patrimoni Bibliogràfic de Catalunya està gestionat per la Biblioteca de Catalunya i creat el 1983 per catalogar, preservar i difondre els patrimoni bibliogràfic catalàviii. El CCPBC és un projecte de catalogació cooperativa obert a totes les institucions, tant públiques com privades, que posseeixen fons bibliogràfics de caràcter patrimonial.

En aquests sentit, cal precisar que l'univers de biblioteques públiques patrimonials de Catalunya l'hem localitzat en el de CCPBC. Els requeriments de doble presencia els han complert onze biblioteques:

- Biblioteca Pública de Lleida

- Biblioteca Pública de Tarragona

- Biblioteca Pública de Girona

- Biblioteca P. Gual i Pujadas (Canet de Mar)

- Biblioteca Comarcal Josep Finestres (Cervera)

- Biblioteca Lambert Mata (Ripoll)

- Biblioteca Margarida de Montferrat (Balaguer)

- Biblioteca Marià Vayreda (Olot)

- Biblioteca Central de Terrassa

- Biblioteca Central Xavier Amorós (Reus)

- Biblioteca Jordi Rubió i Balaguer (Sant Boi de Llobregat) 


\section{Metodologia per la validació qualitativa del model.}

\section{L'entrevista}

Per l'entrevista hem creat un qüestionari expressament per l'ocasió, doncs no s'ha trobat cap model que s'adapti a les nostres necessitats d'explorar l'estat de la qüestió del patrimoni bibliogràfic a les biblioteques públiques de Catalunya d'acord amb els objectius dels treball pel que fa als camps: Biblioteca-Patrimoni (origen); Fons; Ubicació; Instal-lacions i manteniment; Serveis i horaris; Usuaris; Personal; Difusió i Altres.

Per garantir la fiabilitat de l'entrevista aquesta ha estat programada i semiestructurada. En la redacció dels enunciats hem procurat que els tots tinguin el mateix significat per a els entrevistats i que les preguntes es facin en el mateix ordre. També, seguin les recomancions de Merton (1990) hem exposat als entrevistats la situació concreta a partir del previ anàlisi de contingut i de la hipòtesi derivada de la realitat estudiada.

\section{El qüestionari}

\section{Bloc 1: Col-lecció -procedència-}

1.1 Quan es va crear la biblioteca?

1.2 Per què es va crear?

1.3 Quin paper va tenir el patrimoni en l'origen de la biblioteca?

\section{Bloc 2: Fons}

2.1 Quants documents formen la col-lecció?

2.2 Quin és el límit cronològic de la col·lecció?

2.3 De quina temàtica són els documents?

2.4 De quins autors? Destaca algun?

2.5 Quins tipus de documents formen el fons de patrimoni bibliogràfic?

Manuscrits?

Incunables?

Gravats?

Mapes?

Impresos?

2.6 Teniu noves adquisicions?

2.7 Quan es va incloure el fons en el CCPBC?

2.8 Qui es va encarregar de catalogar? 
Bloc 3: Ubicació, instal-lacions i manteniment

3.1 Ocupa un espai diferenciat en la biblioteca?

3.2 Com és el mobiliari on està ubicat?

3.3 Rep algun tipus de manteniment especial al de conjunt de la biblioteca?

\section{Bloc 4: Serveis i horaris}

4.1 Quins són els serveis relacionats amb el fons antic?

4.2 On es poden consultar els documents?

4.3 La consulta als documents sempre és física?

4.4 Quin és el procediment a seguir per consultar els documents?

4.5 Es poden fer reproduccions?

4.6Com poden saber els usuaris els documents de col-lecció de la biblioteca?

4.7Teniu tot el fons catalogat? Quants documents falten (aproximadament)?

4.8 Disposeu de sistemes de recuperació específics, elements distintius

al catàleg?

4.9 Quin és el horari de consulta?

\section{Bloc 5: Usuaris}

5.1 Quins tipus d'usuaris són els interessats en aquests fons?

5.2 Quines necessitats d'informació tenen?

5.3Quines són les finalitats de les seves consultes?

5.4 Quin nivell de formació com a usuaris tenen?

5.5 Realitzeu algun tipus de formació d'usuaris específica per aquests fons?

5.6 Dificultats que suposa l'atenció a aquests usuaris?

5.7 Nombre de consultes durant l"any 2013?

\section{Bloc 6: Personal}

6.1 Quantes persones estan assignades al fons patrimonial?

6.2 A temps complet/parcial?

6.3 Formació del personal?

\section{Bloc 7: Accions de difusió}

7.1 Realitzeu accions de difusió d'aquest fons?

7.2 Quines?

7.3 Feu alguna activitat de cooperació amb altres individus i/o entitats locals/comarcals?

7.3 Quines?

\section{Bloc 8: Altres}

8.1 Quines dificultats suposa la gestió d'aquest fons?

8.2 Heu pensat o teniu necessitat d'algun tipus de mecenatge? 
MEI, II, Vol. 6, no 11 , pág. 223

Quin tipus d'ajuda rebeu de l'administració i que els hi demanaríeu?

8.4 En el conjunt de la vostra biblioteca què suposa disposar de fons bibliogràfic?

A la taula es relacionen els objectius del qüestionari, els blocs i preguntes:

\begin{tabular}{|c|c|c|c|}
\hline Objectius & Blocs del Q & Justificació dels blocs & $\begin{array}{l}\text { Correspondènc } \\
\text { ia amb les } \\
\text { preguntes }\end{array}$ \\
\hline $\begin{array}{l}\text { 1. Identificar Ia } \\
\text { procedèn cia de } \\
\text { la col-lecció }\end{array}$ & $\begin{array}{l}\text { Col-lecció- } \\
\text { procedència }\end{array}$ & $\begin{array}{l}\text { Coneixer l'origen de la bib lioteca } \\
\text { i la imcidència del fons } \\
\text { patrimonial en aquest origen }\end{array}$ & Bloc 1 \\
\hline $\begin{array}{l}\text { 2. Conèixer la } \\
\text { tipologia del } \\
\text { fons }\end{array}$ & Fons & $\begin{array}{l}\text { Determinar les característiques } \\
\text { del fons }\end{array}$ & Bloc 2 \\
\hline \multirow{2}{*}{$\begin{array}{l}\text { Caracteritzar } \\
\text { l'espai destinat a } \\
\text { la seva consulta } \\
\text { i conservació }\end{array}$} & \begin{tabular}{|l|} 
Ubicació, \\
instal-Iació i \\
manteniment
\end{tabular} & Conèixer l'espai i el manteniment & Bloc 3 \\
\hline & \begin{tabular}{|l|}
$\begin{array}{l}\text { Serveis } \quad \mathrm{i} \\
\text { horaris }\end{array}$ \\
\end{tabular} & $\begin{array}{l}\text { Especificar els serveis al póblic i } \\
\text { l'horari que s'ofereixen }\end{array}$ & Bloc 4 \\
\hline \multirow{2}{*}{$\begin{array}{l}\text { 4. Descriure el } \\
\text { perfil dels grups } \\
\text { d'usuaris i els } \\
\text { requerim ent } \\
\text { d'informació } \\
\text { que plantegen en } \\
\text { relació al } \\
\text { patrimoni } \\
\text { bibliogràfic }\end{array}$} & Usuaris & $\begin{array}{l}\text { Determinar la tipologia dels seus } \\
\text { usuaris i de les seves necessitats } i \\
\text { demandes. }\end{array}$ & Bloc 5 \\
\hline & Personal & Valorar la dedicació del personal & Bloc 6 \\
\hline \multirow[t]{2}{*}{5.} & $\begin{array}{l}\text { Accions de } \\
\text { difusió }\end{array}$ & $\begin{array}{l}\text { Saber les accions de difusió de la } \\
\text { biblioteca }\end{array}$ & Bloc 7 \\
\hline & Altres & $\begin{array}{l}\text { Determinar les dificultats, } \\
\text { mancances, necessitats d'aquest } \\
\text { patrimoni i la valoració dels } \\
\text { directius sobre la relació } \\
\text { biblioteca-patrim oni. }\end{array}$ & Bloc 8 \\
\hline
\end{tabular}




\section{L’univers}

Tot i que en la recerca qualitativa el mostreig intencionat és el més habitual en aquest estudi treballarem amb tot un univers de biblioteques, de les que volem obtenir informació, un fet possible per tractar-se de onze. Les biblioteques públiques de Catalunya que pertanyen alhora al SLPC i al CCPBC.

Un univers petit té alguns avantatges: un major control en la investigació, examinar tota la població i poder conèixer la distribució que presenten les variables estudiades.

D’altra banda, el nombre reduït no ha estat impediment per poder aconseguir durant el procés l'acumulació suficient d'entrevistes fins assolir el punt de saturació. Hem pogut copsar totes les dimensions d'interès de manera que els resultats de noves entrevistes no aportarien informació rellevant per la investigació (Vela, 2008).

La nostra intenció era obtenir informació de persones d'aquestes institucions que siguin considerats experts dins de l'àmbit que ens proposem explorar. Amb aquesta premissa ens hem posat en contacte amb les directores de les diferents biblioteques i elles mateixes han seleccionat la persona amb el coneixement més representatiu de la situació a investigar. El resultat és que de les deu biblioteques visitades, en sis la directora era la persona assignada, en dues la directora estava acompanyada de la bibliotecària responsable, en una era la coordinadora de serveis i en una altra una bibliotecària.

\section{El treball de camp}

L'èxit d'una entrevista depèn en gran part de les qualitats de l'entrevistador que ha de presentar una sèrie d'habilitats i de competències per tal de dur a terme una comunicació de profit (Merlinsky, 2006).

És fonamental que l'entrevistador conegui el tema amb profunditat i que utilitzi un llenguatge clar i un discurs estructurat. També és important escoltar atentament a l'entrevistat, sense interrompre'l i estar preparat per girs imprevistos durant la conversa (Kvale, 1996). 
A l'hora de realitzar les entrevistes hem seguit les següents fases (Rubin, 1995):

\begin{tabular}{|c|c|c|c|c|c|c|}
\hline \multicolumn{7}{|c|}{ FASES DE L'ENTREVISTA } \\
\hline 1 & 2 & 3 & 4 & 5 & 6 & 7 \\
\hline $\begin{array}{l}\text { Breu In- } \\
\text { troducció } \\
\text { al tema. } \\
\text { Xerrada } \\
\mathrm{col} \cdot \text { loqui } \\
\text { al. }\end{array}$ & $\begin{array}{l}\text { Crear } \\
\text { confiança } \\
\text { i provo- } \\
\text { car la } \\
\text { conversa }\end{array}$ & $\begin{array}{l}\text { Escoltar } \\
\text { atenta- } \\
\text { ment i } \\
\text { amb em- } \\
\text { patia }\end{array}$ & $\begin{array}{l}\text { Obtenir } \\
\text { descripci- } \\
\text { ons bàsi- } \\
\text { ques }\end{array}$ & $\begin{array}{l}\text { Abordar } \\
\text { preguntes } \\
\text { difícils/ } \\
\text { sensibles }\end{array}$ & $\begin{array}{l}\text { Utilitzar } \\
\text { un llen- } \\
\text { guatge } \\
\text { entene- } \\
\text { dor }\end{array}$ & $\begin{array}{l}\text { En acabar, } \\
\text { formular } \\
\text { agraï- } \\
\text { ments i } \\
\text { obrir pos- } \\
\text { sibilitats a } \\
\text { nous con- } \\
\text { tactes }\end{array}$ \\
\hline
\end{tabular}

La transcripció de les respostes les realitzava l'entrevistador durant l'entrevista, omplint el formulari. Encara que aquests mètode podia alentir o fins i tot aturar el ritme i fluïdesa de la conversa, assegurava una correcta interpretació de preguntes i respostes. La traducció del llenguatge oral a l'escrit implica algunes modificacions i interpretacions, fer-ho amb l'entrevistada representa realitzar una transcripció consensuada i sense errades.

Tot i amb això, les entrevistes transcrites s'han enviat uns dies desprès a les persones entrevistades per la seva validació.

\section{Anàlisi dels resultats}

Presentem els resultats obtinguts en taules seguint el mateix ordre dels blocs i les preguntes del qüestionari emprat: 
MEI, II, Vol. 6, no 11, pág. 226

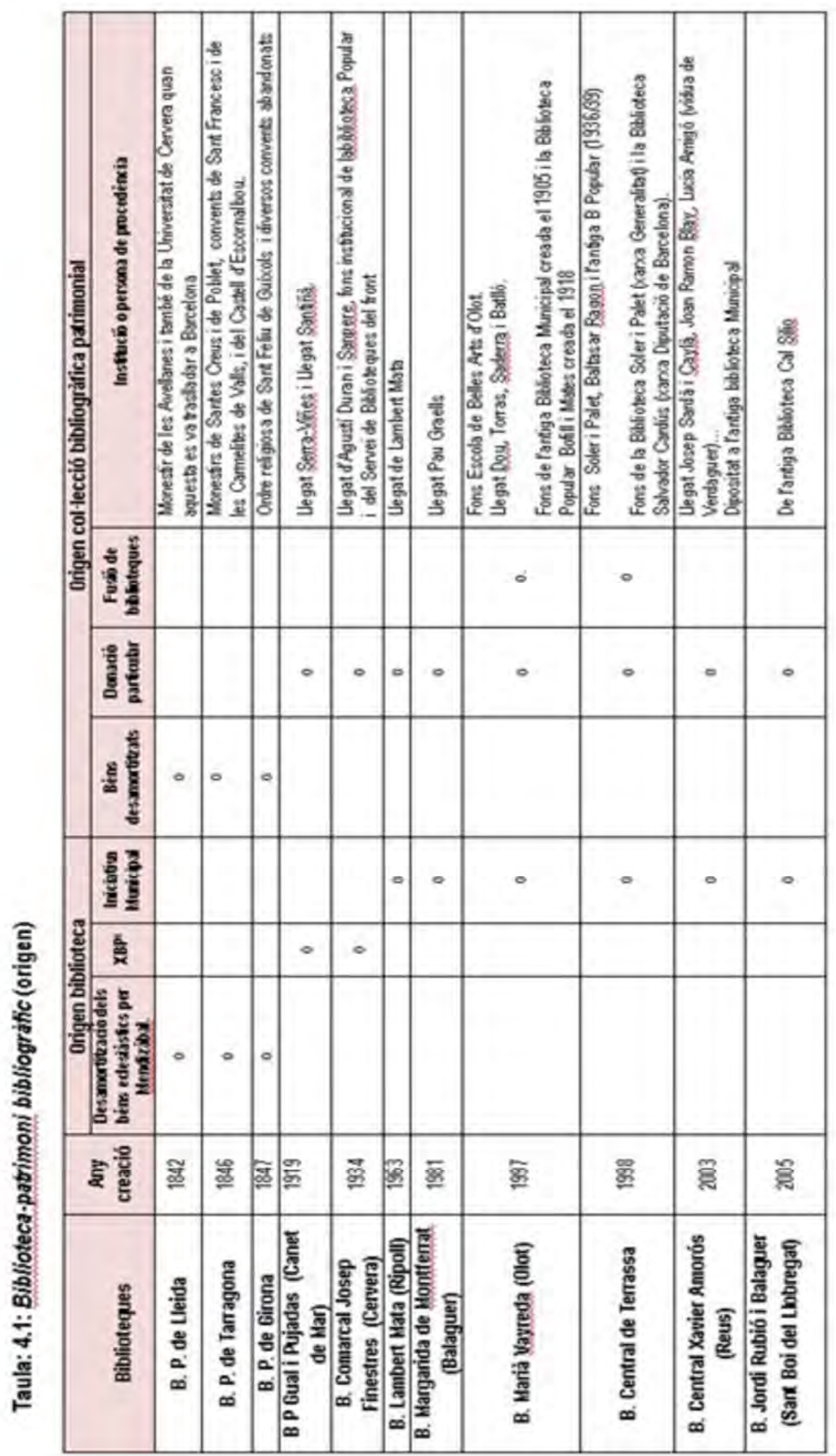


MEI, II, Vol. 6, no 11, pág. 227

\begin{tabular}{|c|c|c|c|c|c|c|c|c|c|c|c|}
\hline 竞 & 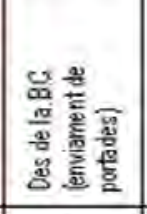 & 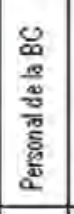 & 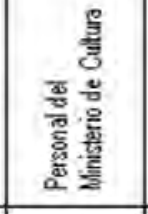 & 1 & 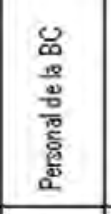 & 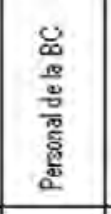 & 1 & 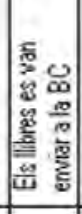 & 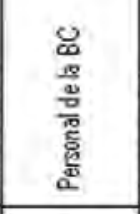 & 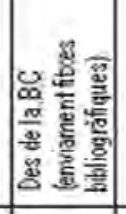 & 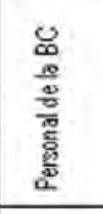 \\
\hline 密兽 & 䒚 & 䍕 & 哴 & I & : & \% & 1 & $\bar{\sigma}$ & 욜 & 畳 & 总 \\
\hline$\frac{\frac{5}{2}}{\frac{2}{2}}$ & 2 & $\bar{\omega}$ & क & 2 & 2 & $\hbar$ & 2 & 2 & 2 & 2 & $\stackrel{2}{2}$ \\
\hline है & & 。 & 0 & & & & & & 0 & & \\
\hline : & & & $\therefore$ & 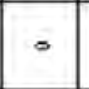 & & & & $\circ$ & & 0 & \\
\hline se & $\circ$ & 0 & $\circ$ & 0 & 0 & 0 & 0 & 0 & 0 & 0 & 0 \\
\hline 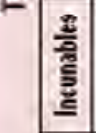 & 0 & $=$ & $=$ & $=$ & & 0 & & $=$ & & $=$ & 0 \\
\hline 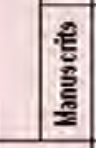 & o & $\Rightarrow$ & 0 & 0 & $\circ$ & $\circ$ & & $=$ & 0 & & \\
\hline $\begin{array}{l}\text { हैँ } \\
\text { हूँ } \\
\text { हैँ }\end{array}$ & 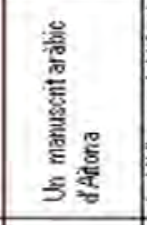 & 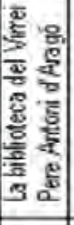 & 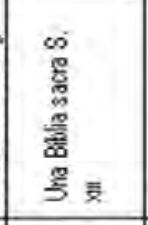 & 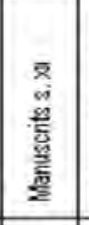 & 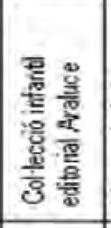 & 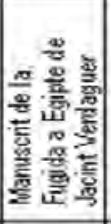 & 1 & 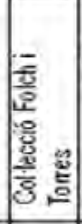 & 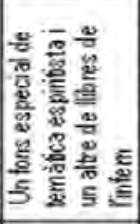 & 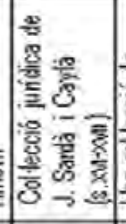 & 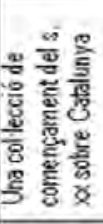 \\
\hline 胥 & 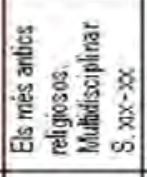 & 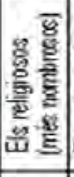 & 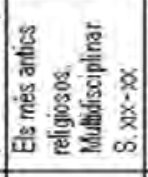 & 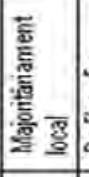 & 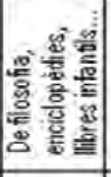 & 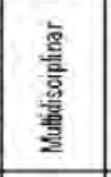 & 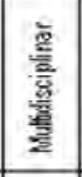 & 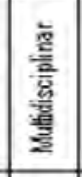 & 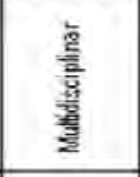 & 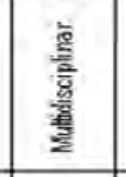 & 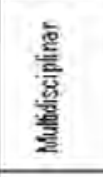 \\
\hline 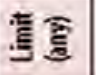 & 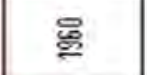 & 哭 & 할 & 兽 & 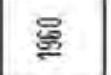 & $\bar{g}$ & 1 & $\stackrel{\infty}{\%}$ & 颟 & 总 & $\approx$ \\
\hline 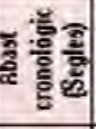 & 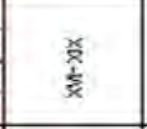 & $\begin{array}{l}\frac{x}{x} \\
\frac{x}{x}\end{array}$ & $\frac{8}{\frac{8}{1}}$ & $\begin{array}{l}\not{p} \\
\frac{1}{\bar{\alpha}}\end{array}$ & 接 & $\begin{array}{l}\frac{x}{2} \\
\frac{1}{2}\end{array}$ & $\begin{array}{l}\not{x} \\
\text { 产 } \\
\frac{1}{2}\end{array}$ & $\begin{array}{l}\frac{x}{\frac{1}{2}} \\
\frac{1}{2}\end{array}$ & 希 & 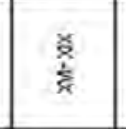 & $\frac{\dot{x}}{\frac{1}{k}}$ \\
\hline 苋 & 㣽 & 을 & 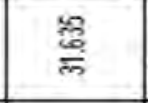 & 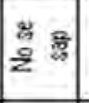 & 岁 & 흥 & 1 & 을 & $\underset{\mathscr{\varpi}}{\mathscr{\sim}}$ & $\stackrel{\approx}{\approx}$ & $\infty$ \\
\hline 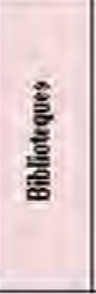 & 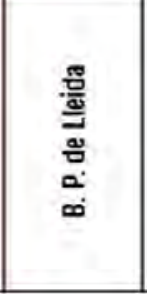 & 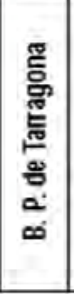 & 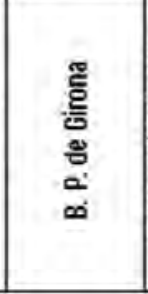 & 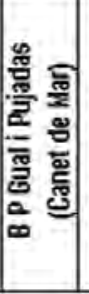 & 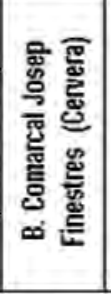 & 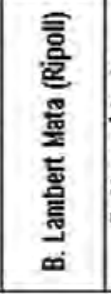 & 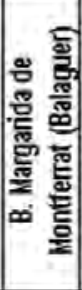 & 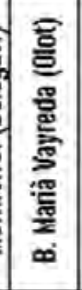 & 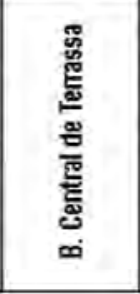 & 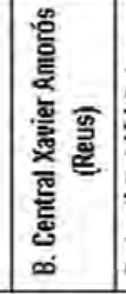 & 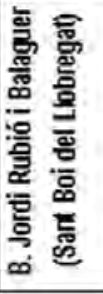 \\
\hline
\end{tabular}


MEI, II, Vol. 6, no 11, pág. 228

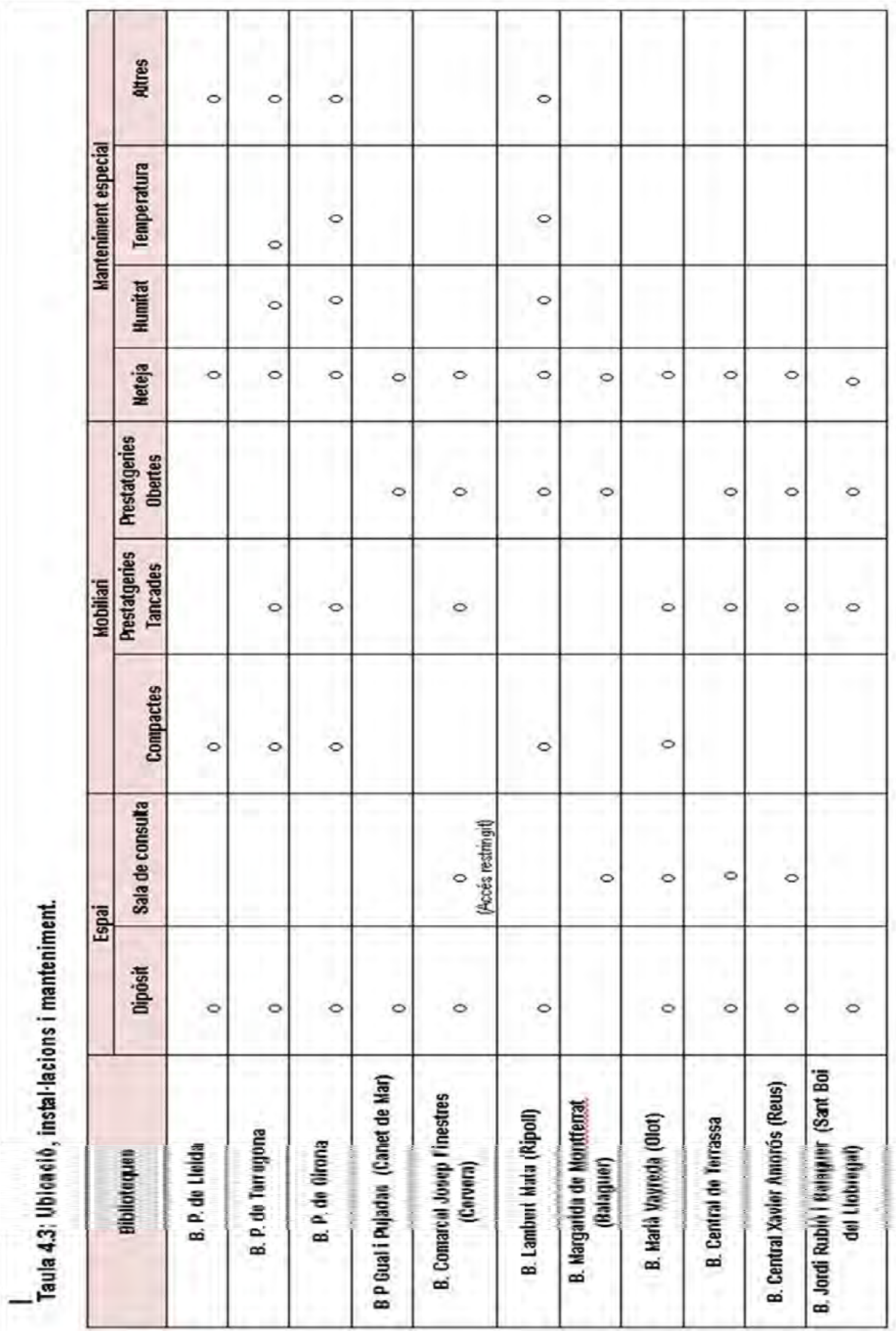


MEI, II, Vol. 6, no 11, pág. 229

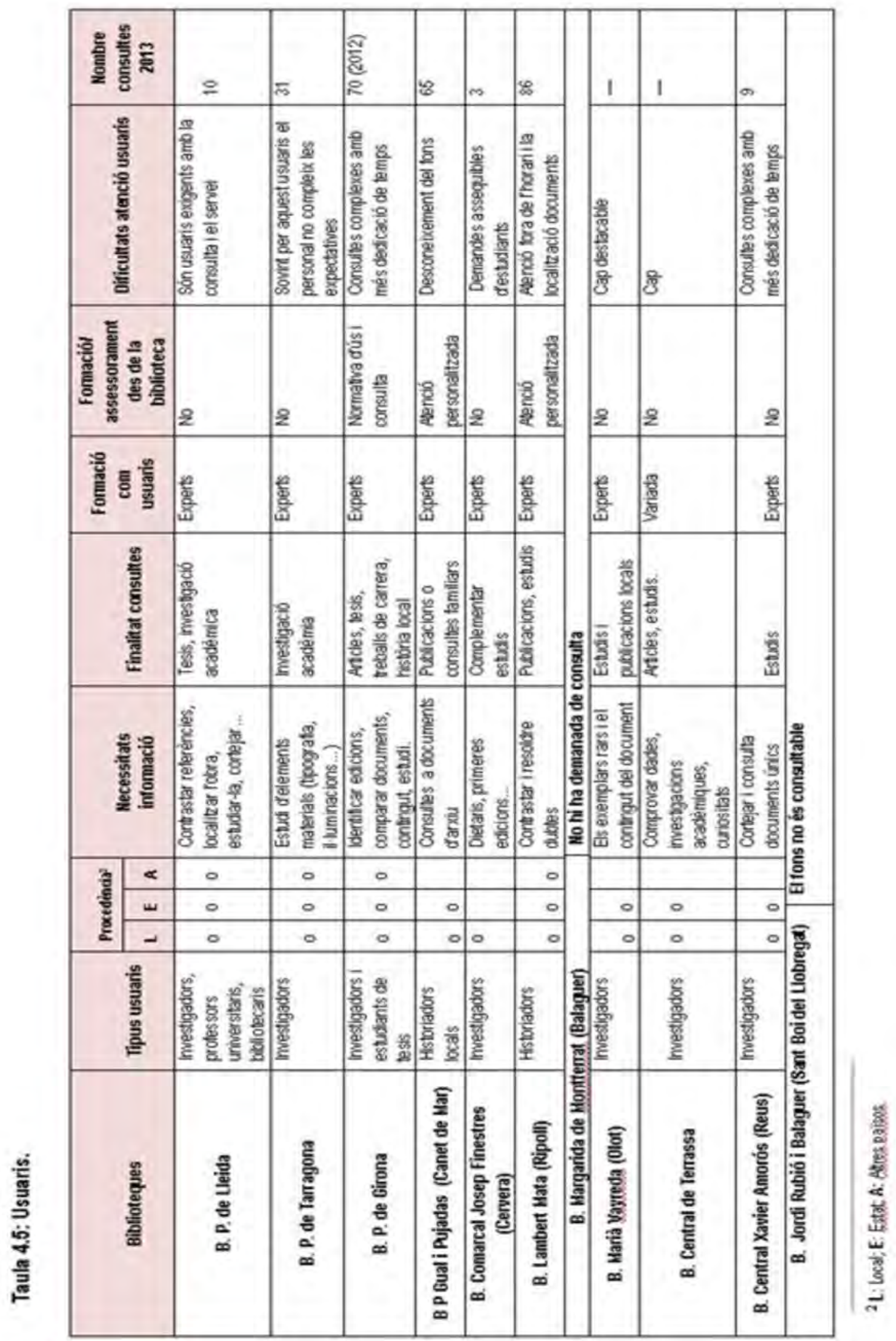


MEI, II, Vol. 6, no 11, pág. 230

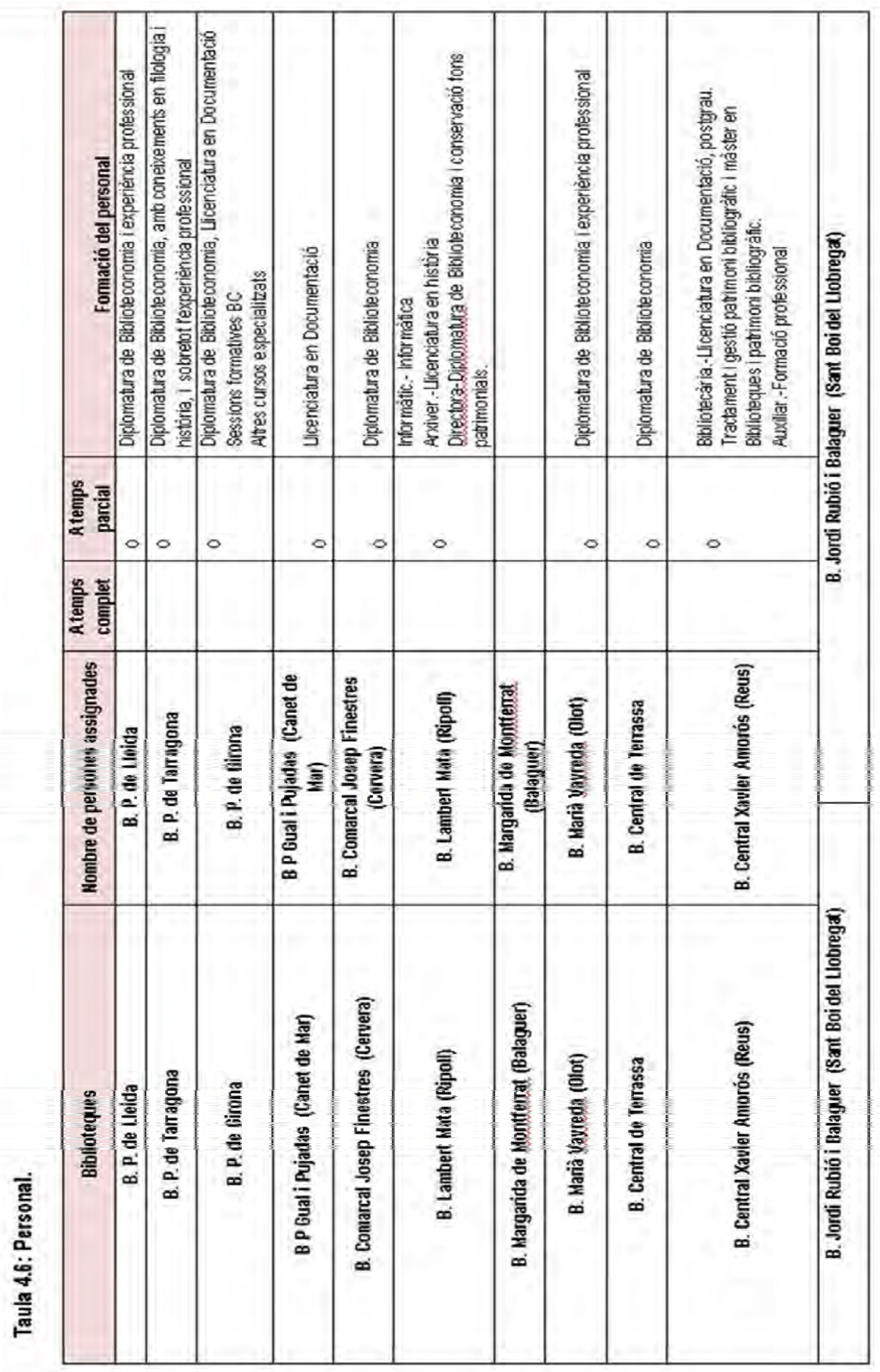


MEI, II, Vol. 6, no 11, pág. 231

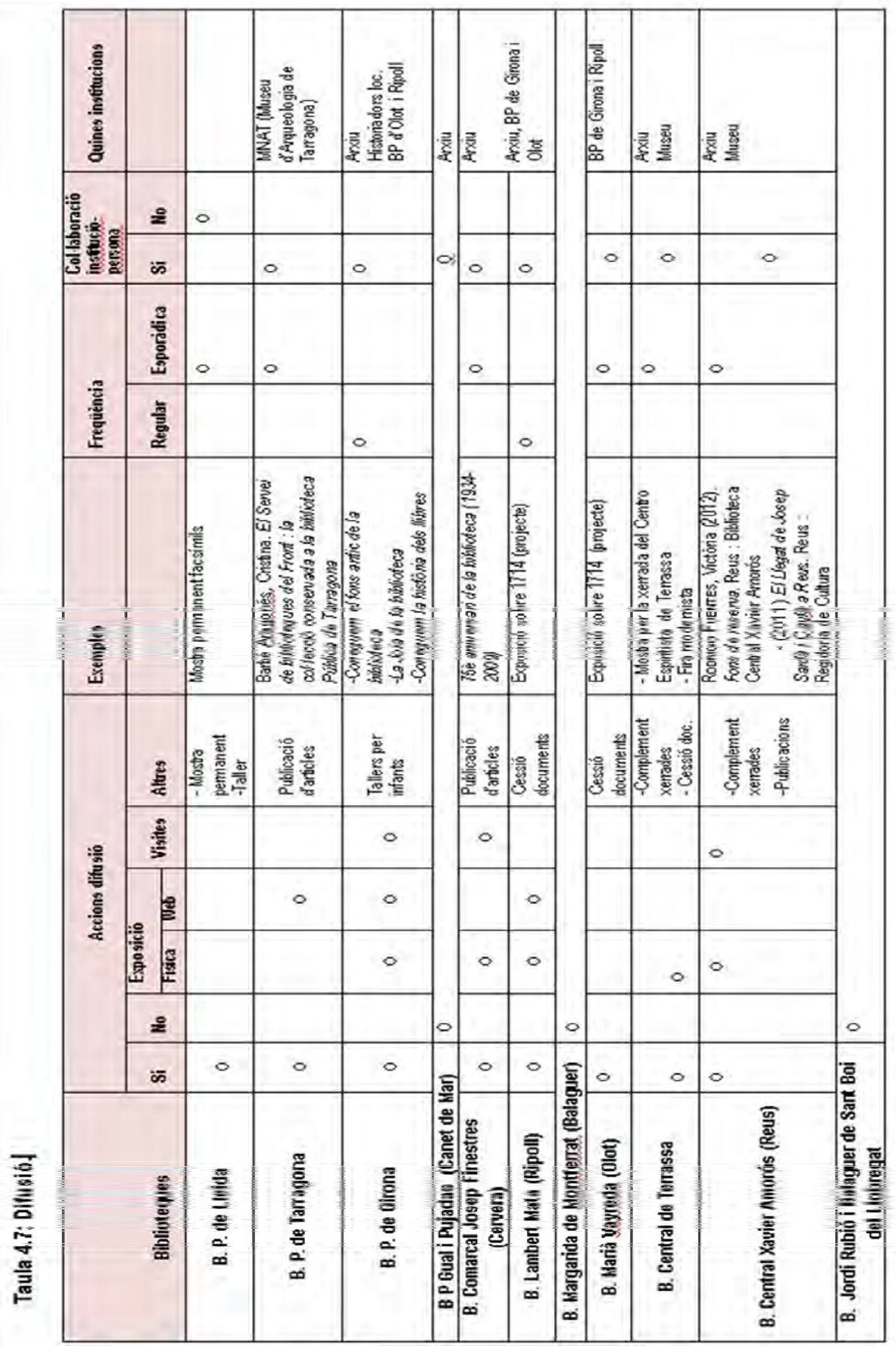


MEI, II, Vol. 6, no 11, pág. 232
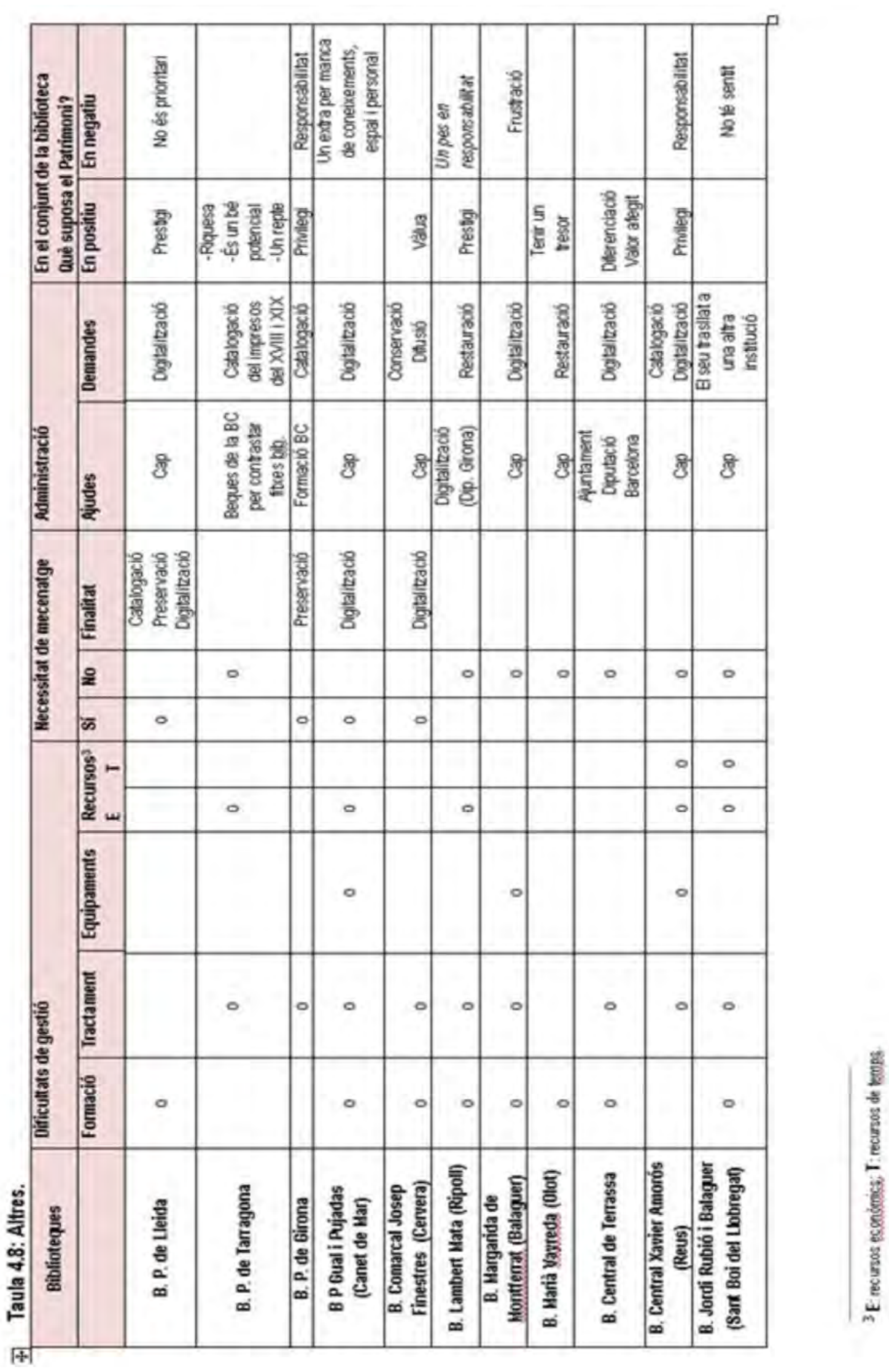


\section{A mode de resum presentem els resultats més destacats:}

- L'origen del fons bibliogràfic de les onze biblioteques és conseqüència de les desamortitzacions de Mendizábal (3 BP provincials), donacions particulars (4 BM) i altres ( 2 BP populars i 2 BP de nova creació).

- Entre totes disposen d'un fons patrimonial format per més de 170.000 documents (manuscrits, impresos, goigs...); de temàtica variada (religió, jurídica, literatura...), en les BP provincials els llibres de religió són els més nombrosos.

- El fons patrimonials en les biblioteques ocupa un espai i té un horari diferenciats. En la majoria de casos l'accés és restringit. Només 4 biblioteques han redactat una política de preservació i conservació del fons.

- Les demandes dels usuaris són poques en comparació amb la resta de serveis de la biblioteca però molt específiques. Cal destacar l'augment creixent de les consultes per Internet, moltes d'elles la fan erudits i investigadors de països estrangers.

- La dedicació del personal és parcial, però ajustada a les necessitats del moment. El coneixement de la matèria l'ha adquirit a través de l'experiència de treball al llarg dels anys i no pas per formació específica.

- Les activitats de difusió relacionades amb el patrimoni bibliogràfic són escasses. I, en molts casos s'organitzen en col·laboració amb altres institucions locals, com ara els arxius.

- Manifesten dificultats de gestió per manca de recursos i formació. El mecenatge és vist amb recel. Altrament, la possessió del patrimoni bibliogràfic és valorat positivament gairebé sempre.

\section{Conclusions}

Les conclusions a les que hem arribat, un cop analitzats els resultats de la investigació són les següents:

- El nombre reduït d'usuaris en comparació a altres serveis de la biblioteca fa que és prioritzin aquests últims.

- La destinació de recursos és escassa perquè el baix nivell de consulta no la justifica. 
- Manca de professionals amb formació específica

- Per la biblioteca posseir una col·lecció bibliogràfica patrimonial suposa un privilegi en tant que constitueix un element identitari que singularitza aporta valor afegit a a la biblioteca.

- Escàs nombre d'activitats de difusió, en solitari o en cooperació, les que actualment es fan a les biblioteques entorn el patrimoni.

De tot plegat es conclouen els següents punts forts i febles:

\section{Punts forts:}

- Espai de memòria

- Aporta prestigi a la biblioteca

- Valor afegit

- Element diferenciador

- Promou la cooperació i la cerca de sinèrgies

\section{Punts febles:}

- Fons desconegut i, per tant, poc consultat

- Dificultats que planteja el tractament documental i garantir la preservació i la conservació. La feina diària d'una BP, no permet ocupar-se'n de les especifitats del patrimoni

Altrament, també, podem constatar que la hipòtesi plantejada es compleix en tots els casos: el patrimoni bibliogràfic de les biblioteques públiques espai privilegiat de memòria- és un bé desconegut per la seva comunitat.

\section{Bibliografia}

ARQUERO AVILÉS, Rosario, 2002. Estudios cualitativos sobre análisis y evaluación de la investigación en biblioteconomía y documentación. Investigación Bibliotecológica, 16 (5-25). INSS 0187-358X

BORREGO HUERTA, Ángel, 1999. La investigación cualitativa y sus aplicaciones en Biblioteconomia y Documentación. REDC, 22 (139-156). INSS O2 10-0614

CEA, M. A., 2004. Métodos de encuesta. Teoría y práctica, errores y mejora. Madrid: Síntesis. ISBN 849756250X 
DÍAZ DE RADA, V., 2005. Manual de trabajo de campo en la encuesta. Madrid: Centro de Investigaciones Sociológicas. ISBN 8474763886

GARCÍA CUETOS, Ma Pilar, 2012. El Patrimonio Cultural. Conceptos Básicos. Zaragoza: Prensas Universitarias de Zaragoza. ISBN 9788415274568 http://travesia.mcu.es/portalnb/jspui/handle/10421/344

IFLA/UNESCO, 1994. Manifiesto de la IFLA/UNESCO sobre la biblioteca pública de 1994. [En linia]. [Consulta: el 20 de setembre de 2015]. Disponible a: http:// unesdoc.unesco.org/images/o011/001121/112122so.pdf

IFLA/UNESCO, 2001. Directrices Ifla/Unesco para el desarrollo del servicio de bibliotecas públicas. [En linia]. Madrid: Ministerio de Educación, Cultura y Deportes. Secretaria de Estado de Cultura.[Consulta: el 20 de setembre de 2015]. Disponible a:

IFLA/UNESCO, 2002. Directrius IFLA/UNESCO pel desenvolupament del servei de biblioteques públiques. [En linia]. Barcelona : Col·legi Oficial de BibliotecarisDocumentalistes de Catalunya. [Consulta: el 20 de setembre de 2015]. Disponible a: http://www.cobdc.org/publica/directrius/IFLA_publiques.pdf

KVALE, S., 1996. Interviews. An introduction to qualitative research interviewing. London : Sage. ISBN 080395820X

MARTÍN MUELA-MEZA, Zapopan, 2006. Una introducción a las metodologías de la investigación cualitativa aplicadas a la bibliotecología. Bibliodocencia: Revista de Professores de Bibliotecología, 2 ( 4-12). INSS 1812-1071

MERLINSKY, G., 2006. La entrevista como forma de conocimiento y como texto negociado : notas para una pedagogía de la investigación. Cinta Moebio, 27(27-33). INSS 0717-554X

MERTON, R.K., 1990: The foucused interview: a manual of problems and procedures . London: Collier Macmillan. ISBN 0029209854

RODRIGO FUENTES, Victòria, 2015. La difusió del patrimonio bibliogràfic a les biblioteques públiques: Un bé per descubrir. Tarragona: Arola Editors. ISBN 978-8494401-65-7

RUBIN, H.J.; RUBIN, I.,1995. Qualitative interviewing. The art of Hearing Data. London: Sage. ISBN 0761920749

RUÍZ OLABUÉNAGA, J.I., 2012. Metodologia de la investigación cualitativa. Bilbao: Universidad de Deusto. ISBN 9788498303360

SÀNCHEZ CRESPO, J.L. 1971. Principios elementales de muestreo y estimación de proporciones. Madrid: INE.

VELA, F., 2008. Un acto metodologico básico de la investigación social : la entrevista cualitativa. A: M.L. Tarrés, coord. Observar, escuchar y comprender. Sobre la tradición cualitativa e la investigación social. México: El Colegio de México, p. 408. ISBN 9789707012028 
MEI, II, Vol. 6, no 11, pág. 236

\section{Notes}

i Les entrevistades han rebut per correu electrònic el qüestionari amb les seves respostes per la validació de la informació.

ii Instrumento de Ratificación de la Convención sobre las medidas que deben adoptarse para prohibir e impedir la importación, la exportación y la transferencia de propiedad ilícitas de bienes culturales hecha en París el 17 de noviembre de 1970. (BOE 05/02/1986). (art. 1.h.).

iii Ley 16/1985, de 25 de junio, del Patrimonio Histórico Español. (BOE 29/06/1985). Al capítol II tracta dels arxius, biblioteques i museus, del seu regim, gestió i competències (art. 59 a 66).

iv Ley 16/1985, de 25 de junio, del Patrimonio Histórico Español. (BOE 29/06/1985). Al capítol II tracta dels arxius, biblioteques i museus, del seu regim, gestió i competències (art. 59 a 66)

v Constitución española de 27 de diciembre de 1978. (BOE 29/12/1978) (art. 44)

vi Llei 4/1993, de 18 de març, del sistema bibliotecari de Catalunya (DOGC núm. 1727, de 29.3.1993)

vii Veure: «http://www20.gencat.cat/docs/Biblioteques/Tematic/Documents/Arxiu/ mapa.pdf»

viii També col-labora amb el Ministeri de Cultura en l'elaboració del catàleg del patrimoni bibliogràfic de l'Estat espanyol. A finals de l'any 2007 el CCPBC es va incorporar al Catàleg Col·lectiu de les Universitats Catalanes (CCUC). 